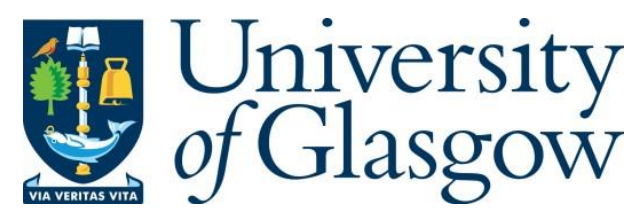

Maughan, P. C., MacFarlane, N. G. and Swinton, P. A. (2021) Relationship between subjective and external training load variables in youth soccer players. International Journal of Sports Physiology and Performance, (doi: 10.1123/ijspp.2019-0956).

There may be differences between this version and the published version. You are advised to consult the publisher's version if you wish to cite from it.

http://eprints.gla.ac.uk/234645/

Deposited on: 22 February 2021

Enlighten - Research publications by members of the University of Glasgow http://eprints.gla.ac.uk 


\title{
Relationship Between Subjective, and External, Training Load Variables in Youth Soccer Players
}

International Journal of Sports Physiology and Performance

Maughan, Patrick; University of Glasgow; Aberdeen Football Club

MacFarlane, Niall; Glasgow University, School of Life Sciences

Swinton, Paul; Robert Gordon University, School of Health Sciences

\begin{abstract}
Purpose: To quantify and describe relationships between subjective and external measures of training load in professional youth soccer players. Methods: Data from differential ratings of perceived exertion and seven measures of external training load were collected from 20 professional youth soccer players over a 46-week season. Relationships were described by repeated measures correlation, principal component analysis and factor analysis with oblimin rotation. Results: Significant positive $(0.44 \leq \mathrm{r} \leq 0.99 ; \mathrm{p}<0.001)$ within-individual correlations were obtained across dRPE and all external training load measures Correlation magnitudes were found to decrease when training load variables were expressed per minute. Principal component analysis provided two components that described $83.3 \%$ of variance. The first component, which described $72.9 \%$ of variance, was heavily loaded by all measures of training load, whilst the second component which described $10.4 \%$ of the variance, appeared to have a split between objective and subjective measures of volume and intensity. Exploratory Factor Analysis identified four theoretical factors with correlations between factors ranging from 0.5 to 0.8 These factors could be theoretically described as; objective volume, subjective volume, objective running and objective high intensity measures. Removing dRPE measures from analysis altered the structure of the model, providing a three factor solution. Conclusions: Differential RPE measures are significantly correlated with a range of external training load measures and with each other. More in-depth analysis showed that dRPE measures were highly related to each other, suggesting that, in this population, they would provide practitioners with similar information. Further analysis provided characteristic groupings of variables
\end{abstract}




\section{INTRODUCTION}

Training load monitoring is common practice in elite sport to develop and prepare athletes ${ }^{1-2}$. Data collected via technology such as GPS can be transformed to create metrics to monitor external training load. The ability to collect valid and reliable field based data has also generated a large amount of applied research that can be used by practitioners to collect and analyse training load data, and also to predict and prescribe future training ${ }^{1}$. Monitoring positional measures of training load such as total distance, velocity, and distance covered at specific speed thresholds are now common in professional team sports ${ }^{2-4}$ as well as accelerometer based metrics such as PlayerLoad ${ }^{\mathrm{TM}} 3$.

In contrast to external measures of training load, rating of perceived exertion (RPE) has been shown to be useful as a tool to measure load ${ }^{5}$. It has been suggested that a global measure of internal training load such as session RPE (sRPE) may lack sensitivity due to large variations in intensity between and within individuals during training and competition ${ }^{6}$. Differential ratings of perceived exertion (dRPE) have been proposed to distinguish between muscular and cardiovascular exertion, thereby providing additional and more detailed information to monitor load ${ }^{7-9}$. Previously, clear between-protocol differences, in relation to dRPE scores have been found during cycling and treadmill based activity ${ }^{9}$. These findings were also supported by between-protocol differences in objective measures of physiological load. Weekly scores of perceived breathlessness (sRPE-B) has been shown to be higher in players who improved YoYo Intermittent Recovery Test Level 1 and countermovement jump, with $18 \pm 11 \%$ and $15 \pm$ $16 \%$ difference between 'responders' and 'non-responders' respectively ${ }^{7}$. McLaren et al ${ }^{10}$ showed that dRPE could isolate specific demands of training. The results showed that differential ratings of breathlessness (sRPE-B) was greatest during field based repeated highintensity effort training, skills and speed-based sessions, whilst upper body muscle exertion (sRPE-U) was highest in resistance training-based sessions. Overall, dRPE explained $77 \%$ of the variance within sRPE training load and the strongest association between the differential markers and sRPE was with measures of leg muscle exertion (sRPE-L). These findings support the notion that different modalities of training will elicit unique training responses, encouraging the use of dRPE in team sports.

Recent research has provided further evidence to support the use of RPE in team sports and as a cost-effective alternative to methods such as GPS monitoring and heart rate analysis. A recent 
meta-analysis across team sports reported positive linear associations between SRPE and various external training load measures ${ }^{11}$. In soccer specifically, whilst sRPE correlates well with external training load measures ${ }^{12}$, correlations tend to be weaker with measures of intensity such as distance covered at high-speeds ${ }^{11,12}$. These lower correlations may reflect the difficulty in obtaining a single measure of intensity to represent the intermittent demands of field sports ${ }^{11}$. Previous research has tended to focus on bivariate correlations that provided limited insight into underlying structure between groups of variables. In contrast, more advanced analyses such as principal component analysis (PCA) and exploratory factor analysis (EFA) may identify structure of relationships between perceived measures of training load and objective measures. Weaving et al ${ }^{13}$ included PCA analysis when exploring the relationships between internal and external measures of load in rugby league players. The authors concluded that across the five variables collected, PCA analysis identified that the structure was different across training methodologies and could often be well explained by two principal components aligning to either internal or external load measures. For example, during skills training the highest loading for the first principal component, which explained almost half the variance was best represented by body load and total impacts. The highest loadings for the second principal component, which explained a further $20.7 \%$ of the variance, was best represented by iTRIMP and sRPE, with component loadings of 0.88 and 0.77 respectively. Additional insights may be obtained employing EFA which provides opportunity to rotate solutions and uncover groupings of measures.

The aim of the current study was to quantify and describe relationships across multiple RPE variables and commonly used measures of external training load in soccer players. Statistical approaches were adopted to provide the most meaningful and useful summary of these relationships. Such understanding would benefit practitioners that only have access to simple RPE measures and provide information to effectively reduce the number of variables that require monitoring to influence decisions on loading. 


\section{METHODS}

\section{Subjects}

Twenty male professional youth soccer players (age: $17.4 \pm 1.3 \mathrm{yrs}$, height: $178.0 \pm 8.1 \mathrm{~cm}$ and weight: $71.8 \pm 7.2 \mathrm{~kg}$ ) were recruited to take part in this study. A total of 3324 individual recordings were taken across the season, consisting of training and match-play. Mean durations $( \pm \mathrm{SD})$ of training and match play are presented in Table 1 . The group comprised multiple positions, with data collected from goalkeepers removed. Rehabilitation sessions were also removed from the analysis leaving a total of 3221 sets of observations. Data collected and the prospective nature of the study conformed to the University of Glasgow research policies in accordance with the declaration of Helsinki.

\section{Design}

The study featured a prospective longitudinal design across an entire 46-week season with professional youth soccer players. The data collection period consisted of a 6-week pre-season and two competitive phases (20-weeks and 19-weeks) split by a 2 -week break. Subjective measures of training load were collected via a range of RPE measures, whereas objective measures of training load were collected via GPS units worn during training and match play. The primary aim of the study was to assess the relationship between subjective and objective measures of training load using a range of statistical techniques.

\section{Methodology}

Each player's global RPE, ratings for breathlessness and ratings for leg muscle exertion were collected, in isolation, approximately 30 minutes after each training session using a standardised scale which has previously been used in soccer (Borg CR10) ${ }^{5}$. All players had previous experience using the scale as part of their training monitoring. Each RPE score was multiplied by session duration to calculate session loads ${ }^{14}$. During training and match-play, players wore commercially available GPS units (Optimeye X4, Catapult Sports, Melbourne, Australia, Firmware version 7.27). These units have been utilised previously in analyses involving team sports ${ }^{15-17}$. Velocity and acceleration dwell times were set at $0.6 \mathrm{~s}$ and $0.4 \mathrm{~s}$ respectively. The units include a GPS receiver and a triaxial accelerometer which collect data at $10 \mathrm{~Hz}$ and $100 \mathrm{~Hz}$ respectively. To avoid interunit error, each player wore the same GPS device for each session. After recording, data were downloaded to a computer and analysed via the 
software package Openfield (Software version 1.19, Catapult Sports, Melbourne, Australia). To minimise differences in data processing, the same software version was used to export training load data ${ }^{1}$. The average satellite count was $10.73 \pm 1.71$, the average horizonal distribution of position was $0.78 \pm 0.2$. The variables selected to quantify external load were total distance (TD, $\mathrm{m})$, PlayerLoad ${ }^{\mathrm{TM}}(\mathrm{PL}, \mathrm{au})$, low intensity running (LIR, $\left.<14.4 \mathrm{~km} \cdot \mathrm{h}^{-1}, \mathrm{~m}\right)$, running (HIR, 19.8 $\left.24.98 \mathrm{~km} \cdot \mathrm{h}^{-1}, \mathrm{~m}\right)$, sprinting $\left(\mathrm{SPR},>24.98 \mathrm{~km} \cdot \mathrm{h}^{-1}, \mathrm{~m}\right)$, accelerations (ACC, $>2 \mathrm{~m} \cdot \mathrm{s}^{-2}$ count) and decelerations (DEC $<-2 \mathrm{~m} . \mathrm{s}^{-2}$, count) expressed in their absolute units and per minute. PlayerLoad ${ }^{\mathrm{TM}}$ is derived from the $100 \mathrm{~Hz}$ tri-axial stored within the receiver and is a measure of external load experienced by players ${ }^{18}$. Running based variables, TD, LIR, SPR, and accelerations and decelerations were included due to their general use practically ${ }^{3}$ and are all measured at $10 \mathrm{~Hz}$.

\section{Statistical Analysis}

Complete data were obtained for almost $90 \%$ of sessions. Where data were missing, these were treated as missing at random and were primarily due to technical errors such as battery failure. Initial assessment of relationships between variables was made using repeated measures correlation to reduce bias ${ }^{12,19}$. The thresholds $<0.10$ (trivial), $0.1-0.3$ (small), $0.3-0.5$ (moderate), 0.5 - 0.7 (large), 0.7 - 0.9 (very large) and > 9 (almost perfect) were used ${ }^{20}$. Comprehensive assessments of relationships across all variables were made using PCA and EFA. PCA is a data reduction technique used to reduce the dimensionality of a dataset whilst maintaining variability ${ }^{13,21,22}$. PCA is an explorative technique that is effective in describing structure among highly correlated variables. PCA produces a set of principal components (linear combinations of the original variables), each containing a set of variables that are correlated with each other; however, the principal components themselves are not correlated. Based on the assumption that data were missing at random, imputation of missing data was made using the imputePCA function from the missMDA package ${ }^{23}$ in the statistical environment R. Suitability of data to perform PCA was assessed using the Kaiser-Meyer-Olkin (KMO) measure of sampling adequacy and the Bartlett test of sphericity ${ }^{24}$. Number of components retained in the analysis was determined by visual inspection of the scree plot and the 'elbow' of the data. Final assessment of underlying structure of relationships between variables was made with EFA. EFA is also a data reduction technique, however whilst PCA 
simply creates linear combinations of the variables, EFA assumes that the measures observed are manifested by latent variables which can be allowed to correlate with each other.

Additionally, solutions can be rotated to assist with useful interpretation of latent variables and as a result the underlying structure. EFA with oblimin rotation was carried out using lavaan version $0.5-23^{25}$ in the statistical environment R. Sensitivity analyses were conducted using the complete cases data set and did not provide any substantive changes, and so all results presented include those generated with the imputed data. 


\section{RESULTS}

Within-individual correlations across dRPE and external load measures are presented in Table 2. All variables measured were positively related to each other $(\mathrm{p}<0.001)$, with correlations from 0.44 to $0.99(\bar{r}=0.71 \pm 0.16)$. Correlations were quantified between perceptual and external variables with measures expressed either per session or per minute (Table 3). Correlations were similar for each of the RPE measures and values were consistently lower when measures were expressed per minute.

PCA provided two readily interpretable principal components with eigenvalues greater than, or equal to, $1\left(\mathrm{PCA} 1_{\text {eig }}=7.3, \mathrm{PCA} 2_{\text {eig }}=1.0\right)$ and cumulatively described $83.3 \%$ of the variance within the dataset (Table 4). The first principal component, which explained $72.9 \%$ of variance, demonstrated substantive contributions from all subjective and objective load variables. The second principal component, which explained $10.4 \%$ of variance, was best represented by contrasting RPE measures and LIR with high intensity activities such as HIR, SPR and ACC (Figure 1).

EFA was conducted, the most appropriate model produced four latent factors (Table 5) with correlations between 0.5 and 0.8 . The correlations between factors ranged from 0.5 to 0.8 . The model had a Tucker-Lewis Index (TLI) of 0.97 and a root mean square error of approximation (RMSEA) of .10 (90\% CI $0.10-0.11)$. TLI and RMSEA are measures of model fit, with a TLI value of equal to or greater than 0.95 considered very good, and an RMSEA between 0.08 to 0.1 considered marginal ${ }^{26}$. Four factors produced were identified as: 1$)$ Objective volume (TD, PL, LIR); Objective running (HIR and SPR); Subjective measures (sRPE, sRPE-L and sRPEB); and 4) Objective high intensity (SPR, ACC, DEC) based on loadings. EFA was carried out with only sRPE from the subjective measures and the most appropriate model included three latent factors $(\mathrm{TLI}=0.967$ and RMSEA 0.12 [90\%CI $0.11-0.13]$ ) identified as: 1$)$ Volume (sRPE, TD, PL and LIR); 2) Intense running (HIR and SPR); and 3) Intense actions (ACC and DEC) (Table 6). 


\section{DISCUSSION}

Understanding the relationships between subjective training load measures and external training load measures can provide practitioners with information to better understand training and match play load. This study aimed to assess the relationship between subjective measures of training load and commonly used objective metrics measured via GPS. Whilst the various measures are positively correlated with each other PCA and EFA provided distinctions between characteristics of metrics. Therefore, there is potential to obtain more useful information by collecting data on multiple variables. However, for the population and physical loads investigated in the present study, the results suggested that RPE measures (sRPE, sRPE-L and sRPE-B) are not distinct and that they are more closely related to objective volume measures of training load than measures of intensity.

The results from the repeated measures correlation suggest that dRPE was related to all measures of external training load and, in line with previous findings ${ }^{12}$, this relationship was weaker when expressed as 'per minute'. Gaudino et al ${ }^{12}$ previously investigated the relationship between sRPE and external measures of training load in professional soccer players. They found that SRPE was significantly related to high speed distance $(\mathrm{r}=.61,95 \% \mathrm{CI}$ .58 - .64), impacts, a combination of collisions and step impacts whilst running, $(\mathrm{r}=.73$, $95 \% \mathrm{CI} .71-.75)$ and accelerations $(\mathrm{r}=.63,95 \% \mathrm{CI} .60-.66)$. This relationship was weaker than when variables were expressed as 'per minute' for RPE and high-speed distance per minute $(r=0.26,95 \%$ CI $0.21-0.30)$, impacts per minute $(r=0.23,95 \%$ CI $0.19-0.27)$ and accelerations per minute $(\mathrm{r}=0.30,95 \% \mathrm{CI} 0.26-0.34)$. These results are similar to our findings where we showed moderate to very large correlations, ranging from 0.44 to 0.86 , between each dRPE reading and external measures of training load, which were then lower, 0.13 to 0.67 , when expressed per minute. Previous research has suggested that this may be due to the multifactorial nature of precepting session intensity ${ }^{12}$. However, we would suggest it is also likely due to the large component of duration in SRPE calculation, and the 'count' nature of the GPS metrics commonly included in studies.

Stronger relationships (Very Large) were measured for sRPE, sRPE-L, and sRPE-B with TD, PL and LIR. These findings are similar to results published by McLaren et al ${ }^{11}$ in team sports which showed "Likely Large" to "Possibly Very Large" inferences between sRPE and accelerometer load and TD respectively. They also showed "Likely Moderate" and "Unclear" relationships between $\mathrm{SRPE}$ and high speed running distance $\left(\geq 13.1-15.0 \mathrm{~km} . \mathrm{h}^{-1}\right)$ and very 
high speed running distance $\left(16.9-19.8 \mathrm{~km} \cdot \mathrm{h}^{-1}\right)$ respectively. McLaren and colleagues ${ }^{11}$ surmised that these differences may be due to a number of factors including; measurement error of GPS devices ${ }^{4,27}$, individual differences in the velocity at which physiologically high intensities are attained ${ }^{28,29}$ or the non-linear relationship between running velocity and internal exercise intensity ${ }^{30}$.

Attempts to move beyond bivariate relationships and assess more in-depth relationships were initiated with PCA. The analysis has been suggested to provide useful information to practitioners as it more clearly indicates the uniqueness between sets of variables. ${ }^{13,31}$. PCA provided two readily interpretable components that cumulatively described $83.3 \%$ of the variance within the dataset. The PCA biplot (Figure 1) displays the eigenvector arrows for each training load variable. The first principal component accounted for $72.9 \%$ of the total variance in the data and represented a relatively simple and equal weighted sum of all the measures. This was expected due to the large positive correlations obtained between all measures and identified that whilst there were aspects of uniqueness, the variables tended to provide similar information and thereby represented a measure of total training load. The second principal component accounted for $10.4 \%$ of the total variance and contrasted RPE measures and LIR with SPR and HIR. This second component could be interpreted as providing differential information between volume and high intensity, or high intensity and perceptions of effort. These findings are similar to those reported by Weaving et $a l^{13}$ with professional rugby league players. The authors also identified more than one principal component for various modes of training with an initial component representing a balanced sum and that subsequent components tended to contrast internal and external load measures.

Weaving et $\mathrm{al}^{13}$ proposed that the intermittent nature of small-sided games leads to a prolonged external-load component, ultimately leading to a high internal load response. As small-sided games were used frequently in the training of the players investigated in the present study, possibly explaining the similarity in results obtained. Conversely, previous research in football showed no correlation between RPE and external load variables, except for a small correlation with PlayerLoad ${ }^{\mathrm{TM}}{ }^{32}$. The findings of Weaving et al. ${ }^{13}$ suggest that during small-sided games, the load measures account for a similar amount of the variance explained by the single principal component suggesting a single measure of training load may be sufficient to monitor training load. Conversely the findings of Casamichana and Julen ${ }^{32}$ suggest that, due to low correlations between measures, a range of indicators are required to best understand training load. Our findings appear to support both arguments for global training. The large amount of 
variance explained by the first principal component support the findings of Weaving et al. ${ }^{13}$, however if practitioners wish to further understand the volume and intensity of training then complementary measures may be required.

The initial EFA identified four latent factors that were interpreted as: 1) objective volume; 2) objective running based; 3) subjective measures; and 4) objective high-intensity measures. Combined with the very high correlations amongst the three RPE measures $(r>0.93)$, these grouping suggest that there was minimal distinction between different RPE measures and that for the population and physical loads investigated there would be limited benefit measuring all three. Removing sRPE-B and sRPE-L from the analysis and only using sRPE as a subjective measure changed the structure of the factor analysis, reducing the model to three-factors, with sRPE aligning with objective measures of volume. Collectively, these findings indicate that for the population and physical loads investigated sRPE-L and sRPE-B providing essentially the same information as SRPE and that this information reflects primarily the training volume completed. Findings regarding dRPE across the literature have been contradictory. McLaren et $a l^{7}$ reported moderate $(10 \% \pm 90 \%$ CL 8.4$)$ differences between weekly sRPE-B and sRPE-L in Championship Rugby Union players. Whereas, Los $\operatorname{Arcos}^{33}$ and colleagues found only trivial differences ( $E S=-0.17 \pm \mathrm{SD} 0.63$ ) between SRPE-B and sRPE-L in young professional soccer players during full match-play. However, further research by McLaren et al ${ }^{9}$ found clear and large differences between sRPE-B and SRPE-L at all time points during incremental treadmill and cycling laboratory based tests. These differences may be due to a number of factors, including the activity assessed, participant demographic and participant familiarity with test protocols. The results from the present findings indicate that in a cohort of youth soccer players, dRPE is unnecessary and does not provide unique information compared with RPE

There are limitations to our study which should be considered. Firstly, we did not include rehabilitation or gym sessions within the analysis. Whilst this does provide an incomplete view of training load across a season, it won't affect the relationship between variables. However, use of different training modalities, such as those used in rehabilitation, may affect the relationship between dRPE measures and support its use. The lack of HR data also didn't allow comparisons between RPE and an objective measure of internal training load, which may provide a better relationship with RPE-B. It could also be argued that RPE is too simplistic a measure to assess diverse physiological goals, however due to its ease of use and relationship 
with internal load it is commonly used in team sports. A recent paper has also suggested its use to monitor biochemical and mechanical stresses, thus again supporting the use of $\mathrm{dRPE}^{34}$. This should be considered by practitioners looking to assess global training load, or more specific load to assess resultant adaptations.

\section{PRACTICAL APPLICATIONS}

- Many internal and external training load measurements provide data that are highly consistent with each other and therefore collection and monitoring of all variables is likely to be inefficient and potentially create unwanted noise.

- Where practitioners have access to GPS or similar technology, unique information can be obtained regarding training load through commonly measured variables.

- In youth soccer players, there does not appear to be unique information provided between sRPE, sRPE-L and sRPE-B, and therefore, with this cohort it appears sufficient for practitioners to monitor sRPE only to attain a measure of training load.

- RPE in youth soccer players appear to be more closely related to external measures of volume. Therefore, if a practitioner does not have access to GPS or similar technology, to best monitor the training load additional measures that more closely link to intensity should be sought.

\section{CONCLUSIONS}

There are strong correlations between sRPE, sRPE-L and sRPE-B, and external training load variables. Variables which could be considered as measures of volume had the strongest correlations. Further analysis showed that 2 principal components explained $83.4 \%$ of the variance in the dataset. The first principal component had large component loadings from all variables, whilst the second had contributions from variables related to high intensity. The large component loadings in the first principal component suggest that these metrics may be providing practitioners with similar information regarding load. Exploratory factor analysis provided four themes, one of which was represented by all dRPE measures. When only including SRPE in the analysis the structure of the factors changed, with SRPE aligning to objective measures of volume. 


\section{Acknowledgements}

This research was conducted with the support of Aberdeen Football Club Development Squad players and staff.

\section{REFERENCES}

1. Malone JJ, Lovell R, Varley MC, Coutts AJ. Unpacking the black box: applications and considerations for using GPS devices in sport. Int J Sports Physiol Perform. 2017;12(s2):S2-18-S12-26.

2. Coutts AJ, Duffield R. Validity and reliability of GPS devices for measuring movement demands of team sports. J Sci Med Sport. 2010;13(1):133-135.

3. Akenhead R, Nassis GP. Training load and player monitoring in high-level football: current practice and perceptions. Int J Sports Physiol Perform. 2016;11(5):587-593.

4. Johnston RJ, Watsford ML, Kelly SJ, Pine MJ, Spurrs RW. Validity and interunit reliability of $10 \mathrm{~Hz}$ and $15 \mathrm{~Hz}$ GPS units for assessing athlete movement demands. $J$ Strength Cond Res. 2014;28(6):16491655.

5. Impellizzeri FM, Rampinini E, Coutts AJ, Sassi A, Marcora SM. Use of RPE-based training load in soccer. Med Sci Sports Exerc. 2004;36(6):1042-1047.

6. Weston M. Difficulties in determining the dose-response nature of competitive soccer matches. J Athl Enhanc. 2013;2(1).

7. McLaren SJ, Smith A, Bartlett JD, Spears IR, Weston M. Differential training loads and individual fitness responses to pre-season in professional rugby union players. J Sports Sci. 2018;36(21):24382446.

8. Jaspers A, Brink MS, Probst SG, Frencken WG, Helsen WF. Relationships between training load indicators and training outcomes in professional soccer. Sports Med. 2017;47(3):533-544.

9. McLaren SJ, Graham M, Spears IR, Weston M. The sensitivity of differential ratings of perceived exertion as measures of internal load. Int J Sports Physiol Perform. 2016;11(3):404-406.

10. McLaren SJ, Smith A, Spears IR, Weston M. A detailed quantification of differential ratings of perceived exertion during team-sport training. J Sci Med Sport. 2017;20(3):290-295.

11. McLaren SJ, Macpherson TW, Coutts AJ, Hurst C, Spears IR, Weston M. The relationships between internal and external measures of training load and intensity in team sports: a meta-analysis. Sports Med. 2018;48(3):641-658.

12. Gaudino P, Iaia FM, Strudwick AJ, et al. Factors influencing perception of effort (session rating of perceived exertion) during elite soccer training. Int J Sports Physiol Perform. 2015;10(7):860-864.

13. Weaving D, Marshall P, Earle K, Nevill A, Abt G. Combining internal-and external-training-load measures in professional rugby league. Int J Sports Physiol Perform. 2014;9(6):905-912. 
14. Foster C, Florhaug JA, Franklin J, et al. A new approach to monitoring exercise training. $J$ Strength Cond Res. 2001;15(1):109-115.

15. Weaving D, Dalton NE, Black C, et al. The Same Story or a Unique Novel? Within-Participant Principal-Component Analysis of Measures of Training Load in Professional Rugby Union Skills Training. Int J Sports Physiol Perform. 2018;13(9):1175-1181.

16. Weaving D, Jones B, Marshall P, Till K, Abt G. Multiple measures are needed to quantify training loads in professional rugby league. Int J Sports Med. 2017;38(10):735-740.

17. Jones RN, Greig M, Mawéné Y, Barrow J, Page RM. The influence of short-term fixture congestion on position specific match running performance and external loading patterns in English professional soccer. J Sports Sci. 2019;37(12):1338-1346.

18. Barrett S, Midgley A, Lovell R. PlayerLoad ${ }^{\mathrm{TM}}$ : reliability, convergent validity, and influence of unit position during treadmill running. Int J Sports Physiol Perform. 2014;9(6):945-952.

19. Bakdash JZ, Marusich LR. Repeated measures correlation. Front Psychol. 2017;8:456.

20. Hopkins W, Marshall S, Batterham A, Hanin J. Progressive statistics for studies in sports medicine and exercise science. Med Sci Sports Exerc. 2009;41(1):3.

21. Kaiser HF. The application of electronic computers to factor analysis. Educ Psychol Meas. 1960;20(1):141-151.

22. Federolf P, Reid R, Gilgien M, Haugen P, Smith G. The application of principal component analysis to quantify technique in sports. Scand J Med Sci Sports. 2014;24(3):491-499.

23. Josse J, Husson F. missMDA: a package for handling missing values in multivariate data analysis. J Stat Softw. 2016;70(1):1-31.

24. Bartlett MS. A note on the multiplying factors for various $\chi 2$ approximations. J R Stat Soc B. 1954:296298.

25. Rosseel Y, Oberski D, Byrnes J, et al. lavaan: Latent variable analysis (Version 0.5-23.1097). In:2017.

26. Dodd AL, Mansell W, Sadhnani V, Morrison AP, Tai S. Principal components analysis of the Hypomanic Attitudes and Positive Predictions Inventory and associations with measures of personality, cognitive style and analogue symptoms in a student sample. Behav Cogn Psychother. 2010;38(1):15-33.

27. Rampinini E, Alberti G, Fiorenza M, et al. Accuracy of GPS devices for measuring high-intensity running in field-based team sports. Int J Sports Med. 2015;36(01):49-53.

28. Buchheit M, Laursen PB. High-intensity interval training, solutions to the programming puzzle. Sports Med. 2013;43(10):927-954.

29. Abt G, Lovell R. The use of individualized speed and intensity thresholds for determining the distance run at high-intensity in professional soccer. J Sports Sci. 2009;27(9):893-898.

30. Faude O, Kindermann W, Meyer T. Lactate Threshold Concepts: how valid are they? Sports Med. 2009;39(6):469-490. 
31. Williams S, Trewartha G, Cross MJ, Kemp SP, Stokes KA. Monitoring what matters: a systematic process for selecting training-load measures. Int J Sports Physiol Perform. 2017;12(Suppl 2):S2-101S102-106.

32. Casamichana D, Castellano J. The relationship between intensity indicators in small-sided soccer games. Journal of human kinetics. 2015;46(1):119-128.

33. Los Arcos A, Méndez-Villanueva A, Yanci J, Martínez-Santos R. Respiratory and muscular perceived exertion during official games in professional soccer players. Int J Sports Physiol Perform. 2016;11(3):301-304.

34. Vanrenterghem J, Nedergaard NJ, Robinson MA, Drust B. Training load monitoring in team sports: a novel framework separating physiological and biomechanical load-adaptation pathways. Sports Med. 2017;47(11):2135-2142. 


\begin{tabular}{|c|c|c|}
\hline Variable & Match values & $\begin{array}{c}\text { Training } \\
\text { Values }\end{array}$ \\
\hline Time (mins) & $72.7 \pm 28.5$ & $58.5 \pm 17.5$ \\
\hline sRPE (au) & $540.6 \pm 291$ & $306 \pm 154.2$ \\
\hline sRPE-L (au) & $550.1 \pm 304$ & $295.2 \pm 173.2$ \\
\hline SRPE-B (au) & $528.8 \pm 294.8$ & $284.2 \pm 167.4$ \\
\hline Total Distance (m) & $8198.4 \pm 3287.6$ & $4413.3 \pm 1563.1$ \\
\hline PlayerLoad (au) & $843.5 \pm 345.8$ & $496.4 \pm 170.4$ \\
\hline LI.Running (m) & $6430.5 \pm 2585$ & $3769.4 \pm 1235.9$ \\
\hline Running (m) & $393.9 \pm 198.8$ & $136.9 \pm 156.5$ \\
\hline Sprinting (m) & $104.2 \pm 92$ & $30.1 \pm 50.9$ \\
\hline Accelerations (count) & $27.9 \pm 15$ & $21 \pm 10.1$ \\
\hline Decelerations (count) & $25.3 \pm 12.6$ & $13.6 \pm 7.8$ \\
\hline RPE & $7.2 \pm 1.8$ & $5.2 \pm 1.7$ \\
\hline RPE-L & $7.5 \pm 1.9$ & $5.4 \pm 1.8$ \\
\hline RPE-B & $7.2 \pm 1.9$ & $5.2 \pm 1.8$ \\
\hline Total Distance.min-1 & $113.7 \pm 12.4$ & $76 \pm 19$ \\
\hline PlayerLoad.min-1 & $11.7 \pm 1.7$ & $8.6 \pm 2$ \\
\hline LI.Running.min ${ }^{-1}$ & $88.7 \pm 9.3$ & $64.1 \pm 12.4$ \\
\hline Running.min ${ }^{-1}$ & $5.6 \pm 2.2$ & $2.7 \pm 4.7$ \\
\hline Sprinting.min ${ }^{-1}$ & $1.6 \pm 1.5$ & $.7 \pm 2$ \\
\hline Accelerations.min ${ }^{-1}$ & $.4 \pm .2$ & $.4 \pm .2$ \\
\hline Decelerations.min ${ }^{-1}$ & $.4 \pm .1$ & $.2 \pm .1$ \\
\hline
\end{tabular}

Table 1 - Load and Intensity measures for match play and training. All differences were significant at $p<0.001$ level.

\begin{tabular}{|c|c|c|c|c|c|c|c|c|c|c|}
\hline & SRPE & SRPE-L & SRPE-B & $\begin{array}{c}\text { Total } \\
\text { Distance }\end{array}$ & PlayerLoad $^{\mathrm{TM}}$ & $\begin{array}{c}\text { LI. } \\
\text { Running }\end{array}$ & Running & Sprinting & Accelerations & Decelerations \\
\hline & $\mathrm{r}$ & $\mathrm{r}$ & $\mathrm{r}$ & $r$ & $\mathrm{r}$ & $r$ & $\mathrm{r}$ & $\mathrm{r}$ & $r$ & $\mathrm{r}$ \\
\hline SRPE & - & .93 & .94 & .86 & .86 & .85 & .62 & .44 & .62 & .7 \\
\hline SRPE-L & & & .97 & .82 & .82 & .82 & .59 & .44 & .58 & .68 \\
\hline SRPE-B & & & - & .82 & .82 & .82 & .59 & .44 & .58 & .67 \\
\hline Total Distance & & & & - & .98 & .99 & .74 & .54 & .65 & .8 \\
\hline PlayerLoad ${ }^{\mathrm{TM}}$ & & & & & - & .98 & .71 & .52 & .67 & .8 \\
\hline $\begin{array}{l}\text { LI. } \\
\text { Running }\end{array}$ & & & & & & - & .65 & .48 & .64 & .78 \\
\hline Running & & & & C & & & - & .68 & .57 & .65 \\
\hline Sprinting & & & & 7 & & & & - & .47 & .58 \\
\hline Accelerations & & & & & & & & & - & .73 \\
\hline
\end{tabular}

Table 2 - Pearson correlations ( $r$ ) for each training load measure. All correlations were significant $(p<0.001)$ and $95 \%$ Confidence Intervals less than \pm 3 units. 


\begin{tabular}{|c|c|c|c|c|c|c|}
\hline Variable & $\begin{array}{l}\text { RPE Corr. } \\
\text { (Magnitude) }\end{array}$ & $95 \%$ CI & $\begin{array}{c}\text { RPE-L } \\
\text { Corr. } \\
\text { (Magnitude) }\end{array}$ & $95 \%$ CI & $\begin{array}{c}\text { RPE-B } \\
\text { Corr. } \\
\text { (Magnitude) }\end{array}$ & $95 \%$ CI \\
\hline \multicolumn{7}{|l|}{ sRPE (Absolute) } \\
\hline Total Distance & $.86(\mathrm{VL})$ & $.85-.87$ & $.82(\mathrm{VL})$ & $.81-.83$ & $.82(\mathrm{VL})$ & $.81-.83$ \\
\hline PlayerLoad ${ }^{\mathrm{TM}}$ & $.86(\mathrm{VL})$ & $.85-.87$ & $.82(\mathrm{VL})$ & $.81-.83$ & $.82(\mathrm{VL})$ & $.81-.83$ \\
\hline LI.Running & $.85(\mathrm{VL})$ & $.84-.86$ & $.82(\mathrm{VL})$ & $.80-.83$ & $.815(\mathrm{VL})$ & $.80-.83$ \\
\hline Accelerations & $.62(\mathrm{~L})$ & $.59-.64$ & $.58(\mathrm{~L})$ & $.56-.61$ & $.58(\mathrm{~L})$ & $.555-.605$ \\
\hline Decelerations & $.70(\mathrm{VL})$ & $.68-.72$ & $.68(\mathrm{~L})$ & $.66-.7$ & $.67(\mathrm{~L})$ & $.65-.69$ \\
\hline \multicolumn{7}{|l|}{ RPE (per min) } \\
\hline $\begin{array}{l}\text { Total Distance per } \\
\text { min }\end{array}$ & $.56(\mathrm{~L})$ & $.54-.59$ & $.55(\mathrm{~L})$ & $.52-.57$ & $.55(\mathrm{~L})$ & $.53-.58$ \\
\hline Running per min & $.295(\mathrm{~S})$ & $.26-.33$ & $.29(\mathrm{~S})$ & $.25-.33$ & $.3(\mathrm{M})$ & $.27-.34$ \\
\hline Sprinting per min & $.14(\mathrm{~S})$ & $.11-.18$ & $.14(\mathrm{~S})$ & $.1-.18$ & $.15(\mathrm{~S})$ & $.12-.19$ \\
\hline $\begin{array}{l}\text { Accelerations per } \\
\text { min }\end{array}$ & $.14(\mathrm{~S})$ & $.11-.18$ & $.13(\mathrm{~S})$ & $.1-.17$ & $.15(\mathrm{~S})$ & $.11-.19$ \\
\hline $\begin{array}{l}\text { Decelerations per } \\
\text { min }\end{array}$ & $.38(\mathrm{M})$ & $.35-.41$ & $.37(\mathrm{M})$ & $.34-.41$ & $.37(\mathrm{M})$ & $.34-.41$ \\
\hline
\end{tabular}

Table 3 - Between-Individual correlations (95\% CI) Between SRPE and RPE and the External Measures of Training Load. Magnitude of the Correlation: $T=$ Trivial, $S=$ Small, $M=$ Moderate, $L=$ Large, $V L=$ Very Large, $N P=$ Near Perfect

\begin{tabular}{|l|c|c|}
\hline & \multicolumn{2}{|c|}{ Component } \\
\hline & 1 & 2 \\
\hline Eigenvalue & 7.29 & 1.04 \\
\hline \% of Variance & 72.9 & 10.4 \\
\hline Cumulative Variance \% & 72.9 & 83.3 \\
\hline Component Loadings & & \\
\hline sRPE & 0.91 & -0.3 \\
\hline sRPEL & 0.89 & -0.34 \\
\hline sRPEB & 0.88 & -0.33 \\
\hline Total Distance & 0.95 & -0.07 \\
\hline PlayerLoadTM & 0.94 & -0.04 \\
\hline LI.Running & 0.93 & -0.15 \\
\hline Running & 0.78 & 0.39 \\
\hline Sprinting & 0.62 & 0.64 \\
\hline Accelerations & 0.74 & 0.31 \\
\hline Decelerations & 0.85 & 0.21 \\
\hline
\end{tabular}

Table 4 - Results of Principal-Component Analysis showing the eigenvalue, percentage of variance explained and cumulative percentage of variance explained by each principal component for all variables. As well as the component loadings for the principal components maintained (PC1 \& PC2). 


\begin{tabular}{|l|l|l|l|l|}
\hline & $\begin{array}{l}\text { MR3 } \\
\text { (Subjective Measures) }\end{array}$ & $\begin{array}{l}\text { MR1 } \\
\text { (Objective Volume) }\end{array}$ & $\begin{array}{l}\text { MR4 } \\
\text { (High Intensity } \\
\text { Objective) }\end{array}$ & $\begin{array}{l}\text { MR2 } \\
\text { (Objective } \\
\text { Running) }\end{array}$ \\
\hline sRPE & .791 & & & \\
\hline sRPEL & .991 & & & \\
\hline sRPEB & 1.016 & & & \\
\hline $\begin{array}{l}\text { Total } \\
\text { Distance }\end{array}$ & & .91 & & \\
\hline $\begin{array}{l}\text { Player } \\
\text { Load }\end{array}$ & & .83 & & \\
\hline LI.Running & & 1.008 & & \\
\hline Running & & & & .922 \\
\hline Sprinting & & & .396 & .504 \\
\hline Accel & & & .720 & \\
\hline Decel & & & .799 & \\
\hline
\end{tabular}

Table 5 - Results of Exploratory Factor Analysis showing the loadings of each factor identified with a cutoff of 0.3

\begin{tabular}{|l|l|l|l|}
\hline & $\begin{array}{l}\text { MR1 } \\
\text { (Volume) }\end{array}$ & $\begin{array}{l}\text { MR3 } \\
\text { (Intense Actions) }\end{array}$ & $\begin{array}{l}\text { MR2 } \\
\text { (Intense Running) }\end{array}$ \\
\hline sRPE & .741 & & \\
\hline Total.Distance & .947 & & \\
\hline PlayerLoad & .852 & & \\
\hline LI.Running & 1.041 & & \\
\hline Running & & & .892 \\
\hline Sprinting & & & .557 \\
\hline Accel & & .743 & \\
\hline Decel & & .805 & \\
\hline
\end{tabular}

Table 6-Results of Exploratory Factor Analysis only including sRPE from subjective measures

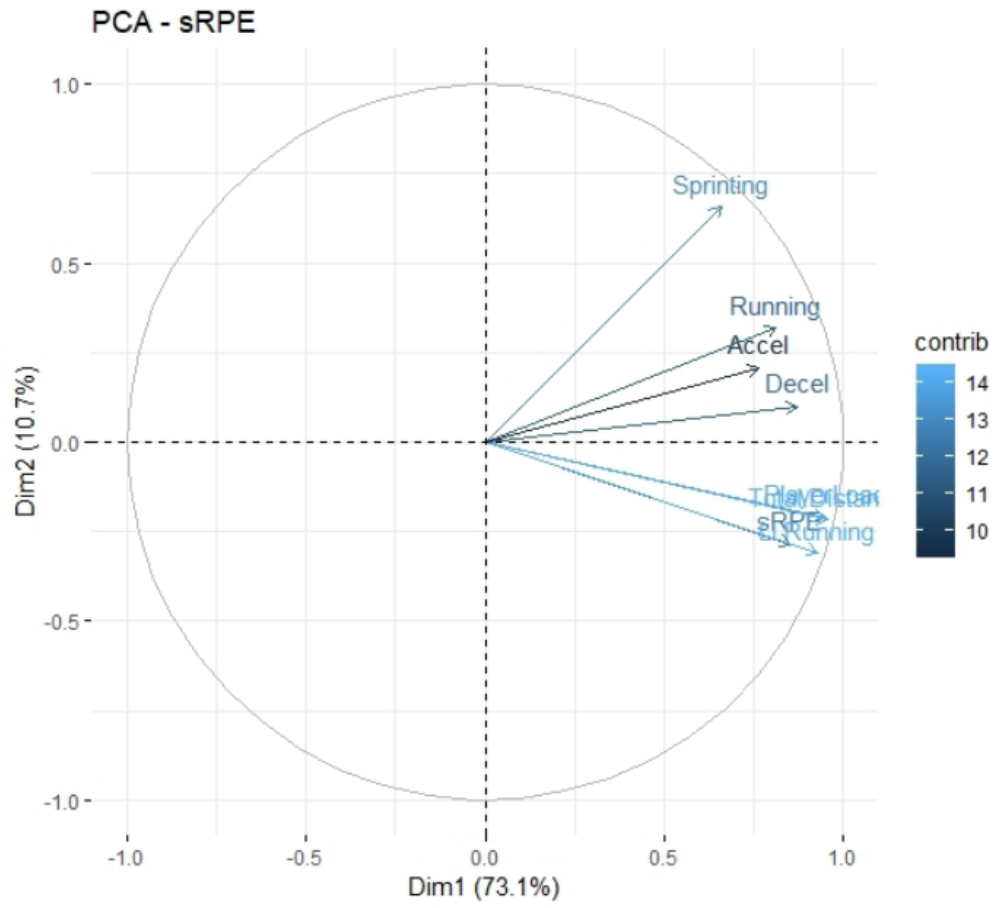

Figure 1 - PCA biplot showing scaled eigenvector arrows for each objective and subjective training load variable. 